\title{
Garbage In, Gospel Out? \\ Controlling for the Underreporting of Remittances
}

\author{
J. Scott Shonkwiler, David A. Grigorian, \\ and Tigran A. Melkonyan
}





\title{
IMF Working Paper
}

Middle East and Central Asia Department

\section{Garbage In, Gospel Out? \\ Controlling for the Underreporting of Remittances}

\author{
Prepared by J. Scott Shonkwiler, David A. Grigorian, and Tigran A. Melkonyan * \\ Authorized for distribution by Erik de Vrijer
}

October 2008

\begin{abstract}

\section{This Working Paper should not be reported as representing the views of the IMF.}

The views expressed in this Working Paper are those of the author(s) and do not necessarily represent those of the IMF or IMF policy. Working Papers describe research in progress by the author(s) and are published to elicit comments and to further debate.
\end{abstract}

Empirical studies that use self-reported data on remittances to measure the latter's impact on microeconomic incentives mostly ignore the potential errors associated with reporting/measurement issues. An econometric procedure to control for these errors is developed and applied to household-level data from Armenia. We find evidence of systematic under-reporting of remittances. After controlling for this, we find a strong negative impact of remittances on incentives to work.

JEL Classification Numbers:C4, D1, D64, D91, J61, O12

Keywords: censored data, measurement error, labor supply, Armenia Authors' E-Mail Addresses: jss@unr.edu; dgrigorian@imf.org; tmelkonyan@,cabnr.unr.edu

\footnotetext{
* J. Scott Shonkwiler and Tigran A. Melkonyan are Professor and Associate Professor, respectively, at Resource Economics Department, University of Nevada, Reno.
} 


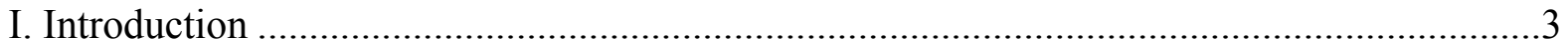

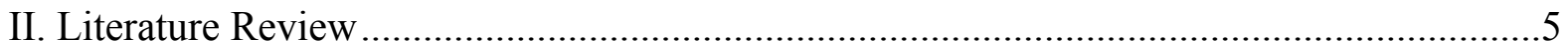

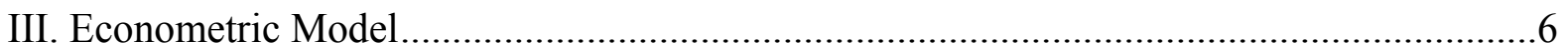

A. Latent treatment of remittances................................................................... 6

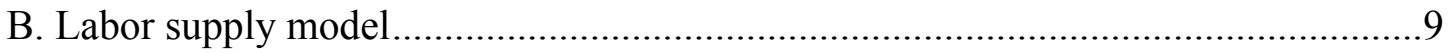

C. Background and Data Description ................................................................

IV. Model Specification and Estimation................................................................. 10

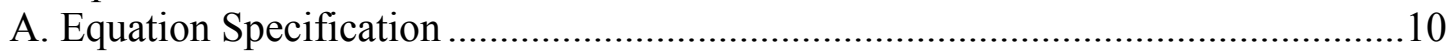

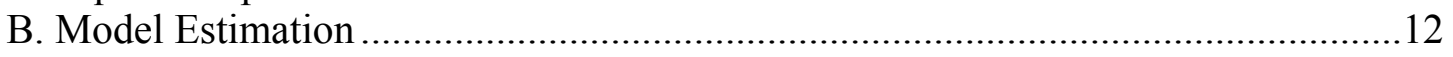

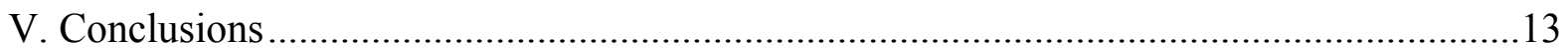

Tables

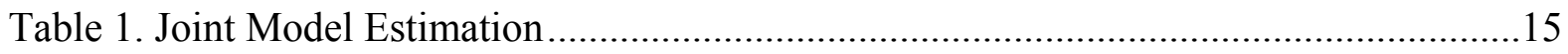

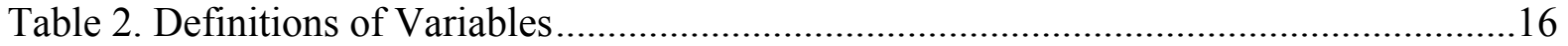

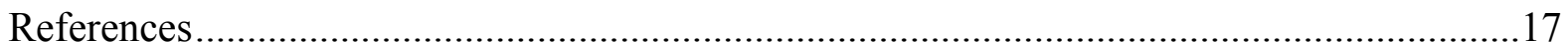




\section{INTRODUCTION}

The world-wide flow of remittances has grown tremendously in recent years, becoming the second source of development finance after foreign direct investment (World Bank, 2005). At the macroeconomic level, the magnitudes of these flows suggest the beneficial nature of remittances for developing nations, despite the challenges of managing such transfers. There is also an acknowledgement in the recent microeconomic literature of the potentially negative impacts of remittances on receiving households' labor supply and investment decisions, education- and health-related expenditures, willingness to migrate, and other decisions. Measuring the signs and magnitudes of these impacts and factoring them into policy formulation, however, is often constrained by availability of good data, and more specifically to data measurement issues.

The recent literature on the impact of remittances on microeconomic incentives ignores the potential errors associated with measurement issues. This is in spite of the fact that a number of authors (e.g., Freund and Spatafora, 2008; Acosta, 2006; Acosta et al., 2006, Roberts, 2004) have noted that remittances tend to be underreported in household survey data. Acosta (2006) notes that for the 1998 nationally representative household survey in El Salvador "the calculated remittances over non-remittance income ratio is 5.9 percent, much lower than the 12.9 percent of remittances over GDP ratio reported in the IMF's Balance of Payment Statistics" (the latter are typically based on aggregate flow data). He further argues that "measurement error in the reported amount received in remittance would introduce a downward bias in the coefficient of the impact of remittances on children's and parent's outcomes. Therefore, even though the present survey asks the total amount received within the year and its uses, it is preferred not to use this amount in the regression analysis." Similarly, Acosta et al. (2006) argue that remittances may be underreported due to the recall bias. More generally, and not surprisingly, it has been observed that survey respondents tend to underreport income (Ravallion, 2003; Freund and Spatafora, 2008).

When a regressor is measured with error, the statistical consequences are well known in the classical regression context. In the case where a conditioning variable is underreported, the relationship between the observed and true variables can be expressed as $\mathrm{X}=\mathrm{X}^{*}-\mathrm{u}$, where $\mathrm{u}$ is a non-negative random variable uncorrelated with the true variable $X^{*}$. If $X$ is absolutely continuous, then the parameter attenuation that occurs by using it as a regressor follows from the fact that $\operatorname{Var}[\mathrm{X}]=\operatorname{Var}\left[\mathrm{X}^{*}\right]+\operatorname{Var}[\mathrm{u}]$. This result is consistent with the standard development of the measurement error model (e.g., Greene, 2003). However if $X$ is censored at zero, the usual errors in variables results must be reconsidered for two reasons.

First, if underreporting leads to a large enough increase in the proportion of zeros, it is possible that $\operatorname{Var}[\mathrm{X}]<\operatorname{Var}\left[\mathrm{X}^{*}\right]$ and hence parameter inflation, rather than attenuation, would result. Second, if $\mathrm{X}$ is treated as a dependent variable in a censored regression model, there is both mismeasurement on the uncensored observations (Stapleton and Young, 1984) and also misclassification of the censored observations. Again, the number of zero observations will be inflated due to underreporting. To correct for these problems, we introduce a new approach to addressing the statistical consequences of underreporting in the context of a 
censored regression that looks at the impact of remittances on labor supply of receiving family members. We use household-level data from Armenia to demonstrate the approach.

Remittances in Armenia constitute a substantial part of many households' income. According to some estimates, remittances in Armenia may have reached 20 percent of GDP in recent years (CBA, 2006). Relatively strong (extended) family ties observed in Armenia (see Alesina and Giuliano, 2007, for a comparison with other countries in the region) may have increased the demand for remittances, resulting in transfers going to households of which the migrant is not an immediate member. ${ }^{1}$ Remittances in Armenia also originate from a large diaspora, the members of which do not necessarily have immediate family in Armenia but remit money to their distant relatives or friends. Thus, we observe a sizable amount of (outof-household) transfers not directly linked with the presence of migrant family members.

Remittance indicators for Armenia are likely to be subject to measurement error. Roberts (2004) suggests that Armenian households may understate remittances by as much as 77 percent. However this number is based on a small convenience sample of emigrants and does not account for transaction costs (Freund and Spatafora, 2008). Given that the survey data we analyze have been collected by an official agency, households may underreport remittances to understate their true income. There are a number of reasons why this could take place. Surveyed individuals may perceive risk in reporting the extent or incidence of remittances, which if reported to relevant agencies, may impact their ability to receive payments and other benefits from the state and foreign aid organizations. Another potential reason - which is likely to be stronger in lower-income neighborhoods - has to do with the tendency of people to understate their wealth/income to limit the demands of poorer relatives and neighbors for loans and advances to support their livelihood. Indeed, only 62 percent of families with migrant members report receiving remittances, a rather low outcome given the strong family ties observed in Armenia.

Uncovering the true effect of remittances on labor supply may help shed light on the impact of remittances on future growth and development prospects of a country. Findings of this paper, which are based on a new methodology, support those reported earlier (see Grigorian and Melkonyan, 2008) on the disincentives created by remittances in Armenia. The results are quite intriguing: we find that remittances reduce incentives to work with an estimated elasticity of labor supply with respect to remittances of about -0.23 .

The issue of underreporting, however, is unlikely to be a country-specific phenomenon or even single issue-specific. The methodology applied in this paper to counter measurement problems is likely to have implications going far beyond the present context of remittancesrelated research on Armenia.

\footnotetext{
${ }^{1}$ Armenia's low divorce rate - with an average of 14.6 percent for 1989-2005, a fraction of that in a number of Central and Eastern European countries - could also serve as an indicator of strong family ties (UNISEF TransMONEE database).
} 
The paper is structured in the following manner. Section II discusses the empirical literature on the determinants of remittances and the impact of remittance flows on labor supply. Section III introduces the econometric model and describes the data. Section IV reports and discusses the econometric estimates. Finally, Section V concludes.

\section{Literature ReVIEW}

The remittances literature has suggested a plethora of motives to remit. A review of the literature that we conducted in detail elsewhere (see Grigorian and Melkonyan, 2008), demonstrates that differences in these motives could have different implications for microeconomic behavior. Factors that influence the likelihood and the amount of remittances include those pertaining to both the remitter as well as the receiving family. As argued by some, more educated migrants are likely to remit less because their migration is more often of a permanent nature (e.g., Faini, 2003). Closeness of family ties could give a boost to both the self-interest and the altruistic motives and have different implications for remittance behavior across countries (e.g., Van Dalen et al., 2005, and Sana and Massey, 2005). Van Dalen et al. (2005) find different patterns across some countries in the Middle East: in Egypt, the presence of a spouse is a strong factor behind remittances, while in Morocco what matters is the presence of a child. Similarly, Sana and Massey (2005) show the difference in remittance patterns in the Dominican Republic and Mexico.

Income levels of receiving families too could be a major determinant of remittances. Osili (2007) uses the U.S.-Nigeria Migration Study to find that poorer origin families tend to receive larger remittances. There is some evidence to suggest that the link between a household's income and migration/remittances is not linear. Minasyan and Hancilova (2005) report that migrants from Armenia are largely from families with average income, suggesting that the low-income households do not have the means to send a migrant abroad, while the rich ones do not have the incentives to do so.

In addition to analyzing the determinants of remittances, the literature has considered the implications of the remittance flows on labor-leisure allocation by recipient households. There are a number of offsetting effects of remittances on labor supply of the remaining household members. One channel is the income effect. If leisure is a normal good then increased household income arising from remittances will tend to decrease labor supply of the remaining household members. On the other hand, the loss of a domestic earner may lead to increased work by the household members left behind. Availability of remittances may also increase self-employment opportunities of the remaining household members by enhancing their opportunities to finance productive investments. Remittances may also result in more schooling of children and young adults which, in turn, may decrease their labor supply. Which of these effects dominates will depend on individual preferences of household members, the production possibilities and the composition of the household, among other factors.

There is ample empirical literature on the effect of remittances on labor supply in developing countries. Selby and Murphy (1982) use a data set for Mexico from the late 1970s and find that households with migrants sent more people into the labor force than households without migrants. Ahlburg (1991) finds that labor force participation of American Samoans receiving 
remittances is lower that that of non-receiving individuals. Funkhouser (1992) finds that in Nicaragua remittances have a negative effect on the labor force participation and a positive effect on self-employment. Although both these effects are significant their magnitudes are small. Itzigsohn (1995) uses data from a survey conducted in four capital cities of the Caribean Basin in 1991 to examine, among other things, the effect of remittances on labor force participation. He finds a negative relationship between receipt of remittances and the probability of labor force participation by the head of household. He also finds evidence that in Santo Domingo and Guatemala remittances have a negative effect on the number of household members that participate in the labor market. In Kingston and Port-au-Prince the effect is insignificant.

More recently, Konica and Filer (2005) found that, while remittances have a significant negative effect on women's participation in the labor market in Albania, the labor force participation of men is not significantly affected by either the existence of emigrants from the household or the amount of remittances received. Amuedo-Dorantes and Pozo (2006) use a nationally representative income and expenditure survey for Mexico to find that while the overall male labor supply does not vary with remittances, its composition does: remittances reduce formal sector work and self-employment for men in urban areas, but increase informal sector work in both urbanized and rural areas. In contrast to men, remittances result in an overall drop in female labor supply coming mostly from reductions in informal sector and non-paid work in rural areas. Acosta (2006) finds that in El Salvador remittances decrease the labor force participation of women and have no significant effect on the labor force participation of men. However, for middle-aged men the relationship between remittances and labor force participation is positive. Yang (2007) finds that as a result of increases in remittances Filipino households raise hours worked in self-employment, and become more likely to start relatively capital-intensive household enterprises. He also finds that these positive income shocks lead to decreased child labor supply. Grigorian and Melkonyan (2008), using a nationally-representative sample from Armenia, report a strongly negative impact of remittances on hours supplied to the market.

\section{ECONOMETRIC MODEL}

\section{A. Latent treatment of remittances}

Let $\mathrm{R}_{\mathrm{i}}$ denote the remittances that are reported to be received by the $i$ th household. Due to the factors outlined above, the actual remittances are hypothesized to be at least as large as those reported by the household. Since the actual remittances, $\mathrm{R}_{\mathrm{i}}{ }^{*}$, are unobserved we posit that:

$$
\mathrm{R}_{\mathrm{i}}=\mathrm{R}_{\mathrm{i}}^{*}-\mathrm{u}_{\mathrm{i}}
$$

The non-negative random variable $\mathrm{u}_{\mathrm{i}}$ is hypothesized to be exponentially distributed:

$$
\mathrm{f}\left(\mathrm{u}_{\mathrm{i}}\right)=\theta \mathrm{e}^{-\theta \mathrm{u}_{\mathrm{i}}} \text { so that } \mathrm{E}\left[\mathrm{u}_{\mathrm{i}}\right]=1 / \theta=\mu \text {. }
$$


Next, assume that actual remittances received by the $i$ th household are related to a set of explanatory variables such as the age/gender composition of the household and whether the household has a member who is a migrant. The model for actual remittances is:

$$
\mathrm{R}_{\mathrm{i}}^{*}=\mathrm{X}_{\mathrm{i}} \beta+\mathrm{v}_{\mathrm{i}}
$$

where $X_{i}$ is a 1xk vector of conditioning variables, $\beta$ is a kx1 vector of coefficients, and $v_{i}$ is a normally distributed random variable with mean zero and variance $\sigma^{2}$.

To express this in terms of observable remittances we substitute for $\mathrm{R}_{\mathrm{i}}{ }^{*}$ to obtain:

$$
\mathrm{R}_{\mathrm{i}}=\mathrm{X}_{\mathrm{i}} \beta+\mathrm{v}_{\mathrm{i}}-\mathrm{u}_{\mathrm{i}}=\mathrm{X}_{\mathrm{i}} \beta+\varepsilon_{\mathrm{i}}
$$

which is a well-known formulation in the stochastic frontier production literature (e.g., Aigner et al., 1977 ). The density for $\varepsilon_{\mathrm{i}}$ is given by

$$
\mathrm{f}\left(\varepsilon_{\mathrm{i}}\right)=\Phi\left(-\frac{\varepsilon_{\mathrm{i}}}{\sigma}-\theta \sigma\right) \theta \mathrm{e}^{\theta \varepsilon_{\mathrm{i}}+\theta^{2} \sigma^{2} / 2}
$$

under the assumption that $v_{i}$ and $u_{i}$ are independent random variables. Here $\Phi($.$) denotes the$ cumulative distribution function of the standard normal. Estimation can be accomplished using the maximum likelihood estimator upon substitution of the observables and unknown parameters, $\mathrm{R}_{\mathrm{i}}-\mathrm{X}_{\mathrm{i}} \beta$, for $\varepsilon_{\mathrm{i}}$. However, reported remittances are strictly non-negative with a substantial proportion of households reporting zero values. Thus, in order to estimate the model in equation (3), we need to account for the censored-at-zero nature of the dependent variable $R_{i}$. Specifically, we need to evaluate the probability that $R_{i} \leq 0$. We have that

$$
\operatorname{Pr}\left(\mathrm{R}_{\mathrm{i}} \leq 0\right)=\operatorname{Pr}\left(\mathrm{X}_{\mathrm{i}} \beta+\varepsilon_{\mathrm{i}} \leq 0\right)=\operatorname{Pr}\left(\varepsilon_{\mathrm{i}} \leq-\mathrm{X}_{\mathrm{i}} \beta\right)=\int_{-\infty}^{-X_{i} \beta} f\left(\varepsilon_{i}\right) d \varepsilon_{i}
$$

Alternatively, we can write this probability as the probability that $R_{i} \leq 0$ given $u_{i}$ and then integrate out $\mathrm{u}_{\mathrm{i}}$. This approach yields:

$$
\begin{aligned}
& \operatorname{Pr}\left(\mathrm{R}_{\mathrm{i}} \leq 0\right)=\operatorname{Pr}\left(\mathrm{v}_{\mathrm{i}}-\mathrm{u}_{\mathrm{i}} \leq-\mathrm{X}_{\mathrm{i}} \beta\right)=\operatorname{Pr}\left(\frac{\mathrm{v}_{\mathrm{i}}}{\sigma} \leq \frac{\mathrm{u}_{\mathrm{i}}-\mathrm{X}_{\mathrm{i}} \beta}{\sigma}\right)=\Phi\left(\frac{\mathrm{u}_{\mathrm{i}}-\mathrm{X}_{\mathrm{i}} \beta}{\sigma} \mid \mathrm{u}_{\mathrm{i}}\right) \\
& =\int_{0}^{\infty} \Phi\left(\frac{\mathrm{u}_{\mathrm{i}}-\mathrm{X}_{\mathrm{i}} \beta}{\sigma}\right) \theta \mathrm{e}^{-\theta \mathrm{u}_{\mathrm{i}}} \mathrm{du}_{\mathrm{i}}
\end{aligned}
$$

To avoid the evaluation of the above integral when performing maximum likelihood estimation, we find, using integration by parts and a change of variable, that:

$$
\operatorname{Pr}\left(\mathrm{R}_{\mathrm{i}} \leq 0\right)=\Phi\left(\frac{-\mathrm{X}_{\mathrm{i}} \beta}{\sigma}\right)+\mathrm{e}^{\theta^{2} \sigma^{2} / 2-\theta \mathrm{X}_{\mathrm{i}} \beta} \Phi\left(\frac{\mathrm{X}_{\mathrm{i}} \beta}{\sigma}-\theta \sigma\right)
$$


The probability in (7) has two non-negative terms. The first term is a standard expression in a conventional censored regression framework. The second one relates to the presence of the one-sided disturbance $u_{i}$ in the evaluation of this probability.

Note that if there is no under-reporting, $\mathrm{E}\left[\mathrm{u}_{\mathrm{i}}\right]=\mu=0$. However, it is not immediately obvious that the second term in equation (7) goes to zero as $\theta \rightarrow \infty$ or equivalently as $\mu \rightarrow 0$. To investigate this, we fix $X_{i} \beta$ arbitrarily, and without any loss of generality, at zero, and rewrite the second term in terms of $\mu=\theta^{-1}$, to obtain:

$$
\lim _{\mu \rightarrow 0} \frac{\Phi(-\sigma / \mu)}{\exp \left(-.5 \sigma^{2} / \mu^{2}\right)}
$$

We then apply L'Hopital's rule to obtain:

$$
\lim _{\mu \rightarrow 0} \frac{\phi(-\sigma / \mu) \sigma / \mu^{2}}{\exp \left(-.5 \sigma^{2} / \mu^{2}\right) \sigma^{2} / \mu^{3}}=\lim _{\mu \rightarrow 0} \frac{\mu / \sigma}{\sqrt{2 \pi}}=0
$$

where $\phi($.$) denotes the standard normal density function. Thus, the conventional result for$ this probability is obtained when $\mathrm{E}\left[\mathrm{u}_{\mathrm{i}}\right]=0$.

However, if there is under-reporting (i.e., $\mathrm{E}\left[\mathrm{u}_{\mathrm{i}}\right]>0$ ), then the second term in equation (7) represents an increased probability of zero reported remittances. The log likelihood for the $i$ th observation on $\mathrm{R}$ then takes into account the censoring at zero according to

$$
\begin{aligned}
\ell_{\mathrm{i}}=\left(1-\mathrm{d}_{\mathrm{i}}\right) \ln \left\{\Phi\left(\frac{-\mathrm{X}_{\mathrm{i}} \beta}{\sigma}\right)+\mathrm{e}^{\theta^{2} \sigma^{2} / 2-\theta \mathrm{X}_{\mathrm{i}} \beta} \Phi\left(\frac{\mathrm{X}_{\mathrm{i}} \beta}{\sigma}-\theta \sigma\right)\right\}+ \\
\mathrm{d}_{\mathrm{i}}\left\{\ln \Phi\left(\frac{\mathrm{X}_{\mathrm{i}} \beta-\mathrm{R}_{\mathrm{i}}}{\sigma}-\theta \sigma\right)+\ln \theta+\theta\left(\mathrm{R}_{\mathrm{i}}-\mathrm{X}_{\mathrm{i}} \beta\right)+\theta^{2} \sigma^{2} / 2\right\}
\end{aligned}
$$

where $d_{i}=1$ if $R_{i}>0$ and $d_{i}=0$ otherwise. As a consequence of censoring, zero outcomes for $\mathrm{R}_{\mathrm{i}}{ }^{*}$ are possible - from (7) we know this probability is $\Phi\left(\mathrm{X}_{\mathrm{i}} \beta / \sigma\right)$. The (unconditional) expected value of $\mathrm{R}_{\mathrm{i}}{ }^{*}$ is given by:

$$
\mathrm{E}\left[\mathrm{R}_{\mathrm{i}}^{*}\right]=\Phi\left(\mathrm{X}_{\mathrm{i}} \beta / \sigma\right) \mathrm{X}_{\mathrm{i}} \beta+\sigma \phi\left(\mathrm{X}_{\mathrm{i}} \beta / \sigma\right)
$$

This follows from evaluating the (unconditional) expectation of $\mathrm{R}_{\mathrm{i}}$. This expectation has the form $\mathrm{E}\left[\mathrm{R}_{\mathrm{i}}\right]=\mathrm{E}\left[\mathrm{R}_{\mathrm{i}} \mid \mathrm{R}_{\mathrm{i}}=0\right] \mathrm{P}\left(\mathrm{R}_{\mathrm{i}}=0\right)+\mathrm{E}\left[\mathrm{R}_{\mathrm{i}} \mid \mathrm{R}_{\mathrm{i}}>0\right] \mathrm{P}\left(\mathrm{R}_{\mathrm{i}}>0\right)$ and integration yields

$$
\mathrm{E}\left[\mathrm{R}_{\mathrm{i}}\right]=\mu \mathrm{e}^{\theta^{2} \sigma^{2} / 2-\theta \mathrm{X}_{\mathrm{i}} \beta} \Phi\left(\frac{\mathrm{X}_{\mathrm{i}} \beta}{\sigma}-\sigma \theta\right)-\mu \Phi\left(\frac{\mathrm{X}_{\mathrm{i}} \beta}{\sigma}\right)+\Phi\left(\frac{\mathrm{X}_{\mathrm{i}} \beta}{\sigma}\right) \mathrm{X}_{\mathrm{i}} \beta+\sigma \phi\left(\frac{\mathrm{X}_{\mathrm{i}} \beta}{\sigma}\right)
$$

Notice that the first two terms on the right hand side of (10) are the correction factors which account for underreporting (i.e., $\mu>0$ ) in the observed $\mathrm{R}_{\mathrm{i}}$; whereas the last two terms comprise 
the conventional unconditional expectation of a censored-at-zero normal variable. If there is underreporting, then the sum of the first two terms on the right hand side of (10) is negative as long as $\mu>0$.

\section{B. Labor supply model}

We propose modeling the household's desired hours supplied to the labor market, $\mathrm{y}_{\mathrm{i}}{ }^{*}$, as a function of actual remittances received by the household, and a vector of household characteristics and regional labor market conditions, $\mathrm{Z}_{\mathrm{i}}$, as follows:

$$
\mathrm{y}_{\mathrm{i}}^{*}=\alpha \mathrm{R}_{\mathrm{i}}^{*}+\mathrm{Z}_{\mathrm{i}} \delta+\eta_{\mathrm{i}}
$$

where $\delta$ is a vector of unknown coefficients and $\eta_{i}$ is assumed to be normally distributed with mean zero and variance $\tau^{2}$.

We observe reported hours supplied to the labor market, $y_{i}$, and relate them to the desired hours according to the following rule:

$$
\begin{aligned}
& \mathrm{y}_{\mathrm{i}}=\mathrm{y}_{\mathrm{i}}^{*} \text { if } \mathrm{y}_{\mathrm{i}}^{*}>0 \text { and define } \mathrm{w}_{\mathrm{i}} \text { as the indicator of this event } \\
& \mathrm{y}_{\mathrm{i}}=0 \text { otherwise and define } 1-\mathrm{w}_{\mathrm{i}} \text { as the indicator of this event. }
\end{aligned}
$$

Consequently reported hours are censored at zero. Maximum likelihood estimation of the parameters in equation (11) must both account for the censoring and for the fact that $\mathrm{R}_{\mathrm{i}}^{*}$ is unobserved. From our results in expression (9), we substitute $E\left[R_{i}^{*}\right]$ for the unobserved $R_{i}{ }^{*}$. Hence, we can estimate $E\left[R_{i}^{*}\right]$ by maximizing the log likelihood given in (8) over the entire sample of remittance data and then evaluate (9). The log likelihood for the censored labor supply model becomes:

$\lambda_{\mathrm{i}}=\left(1-\mathrm{w}_{\mathrm{i}}\right) \ln \Phi\left(\frac{-\alpha \mathrm{E}\left[\mathrm{R}_{\mathrm{i}}^{*}\right]-\mathrm{Z}_{\mathrm{i}} \delta}{\tau}\right)+\mathrm{w}_{\mathrm{i}}\left\{-0.5\left(\mathrm{y}_{\mathrm{i}}-\alpha \mathrm{E}\left[\mathrm{R}_{\mathrm{i}}^{*}\right]-\mathrm{Z}_{\mathrm{i}} \delta\right)^{2} / \tau^{2}-0.5 \ln \left(2 \pi \tau^{2}\right)\right\}$

One additional complication is that the standard errors of the labor supply equation need to reflect the fact that this is a two stage estimation - we are using estimators of $\beta, \mu$ (or $\theta$ ), and $\sigma$ to form $E\left[\mathrm{R}_{\mathrm{i}}^{*}\right]$ according to (9). This can be avoided by jointly specifying (8) and (12) and then estimating all parameters by maximizing both $\Sigma \ell_{\mathrm{i}}$ and $\Sigma \lambda_{\mathrm{i}}$ simultaneously.

\section{Background and Data Description}

Armenia is an interesting, if not extreme, case for studying migration and remittance behavior. A highly industrialized and well-educated society ${ }^{2}$ at the dusk of the Soviet Union,

\footnotetext{
${ }^{2}$ The industrialized and educated nature of the society/labor force is a common feature for many transition countries of the former Soviet bloc. This is also a key difference between this group and many of the Latin American countries that are widely studied in the context of migration and remittances.
} 
Armenia underwent severe economic contractions imposed by the collapse of trade links (following the fall of the Soviet Union) and a full-scale conflict with neighboring Azerbaijan over Nagorno Karabakh during 1991-94. Although some out-migration took place during the conflict itself, an exodus of the population did not begin until it became clear that the government had not delivered on its promises of economic reform after the war. While GDP grew slightly in 1994, after falling by almost half in 1992-93, and inflation was receding from its triple-digit war levels, social conditions were still severe and corruption worsened considerably. The traditional Armenian diaspora in Western countries and Russia was rapidly 'reinforced' by new immigrants, causing Armenia to become one of the top populationexporting countries in the world (measured as a percent of pre-emigration population). ${ }^{3}$ Remittances became a key source of income for many household members and families left behind in Armenia. While generally assumed to be sizable - a sensible assumption in an environment with low wage rates - the underlying incentive effect of remittances on receiving families has not been subject to much research. The question of whether remittances have provided incentives to migrate for those left in Armenia has also not been researched.

For our analysis, we used the 2004 Integrated Living Standards Measurement Survey conducted by the National Statistical Service of Armenia. This is a comprehensive survey covering a wide range of household activities, including migration and remittances. The dataset is nationally representative, containing data for over 28,000 individuals from over 6,800 households (see Grigorian and Melkonyan, 2008, for a more detailed description of this dataset). We consider all households with at least one member who is of working age. Our sample then comprises 6,164 observations.

\section{Model SPECIFICATION ANd Estimation}

\section{A. Equation Specification}

The key issue to tackle while estimating the impact of remittances on economic outcomes is the potential simultaneity of remittances and the economic outcomes in question. We choose a two-step econometric model to help properly identify remittances and their impact on labor supply. We correct for possible underreporting in remittances in the first stage equation to provide an expected value of actual (as opposed to measured/reported) remittances for the second stage equation. Specification of the remittance equation involves both parameterizing the exponential distribution to account for underreporting and specifying a conditional mean function for (continuous) latent remittances.

The mean level of underreporting, $\mu$, was allowed to vary over households according to the function:

\footnotetext{
${ }^{3}$ Official statistics report that 18.4 percent of 1989 population emigrated between 1989 and 2004. The population of Armenia was 3.2 million in 2004 (World Bank, 2006). However, the official population statistics are likely to be overstated allegedly due to national security-related concerns and the opportunities for election manipulation. (For an unofficial estimate of the Armenian population see U.S. Department of State, 2002, and IWPR, 2000.)
} 


$$
\mu_{\mathrm{i}}=\exp \left(\gamma_{0}+\gamma_{1} \operatorname{lnCorrupt}_{\mathrm{i}}+\gamma_{2} \text { BadHouse }_{\mathrm{i}}+\gamma_{3} \ln \text { AvWorkAge }_{\mathrm{i}}\right) .
$$

where, as defined in Table 2, Corrupt is the share of respondents in every region who mentioned corruption as an obstacle for rising living standards; BadHouse is a dummy variable that takes value of 1 if the housing conditions are assessed as bad by the household members; and AvWorkAge is the average age of working-age members of the household. The rationale behind this specification hinges on the following two key considerations. First, underreporting may be related to corruption in the respondent's region. We conjecture that in regions with higher level of corruption, the net transfers (that is, monetary and/or in-kind support provided by the state net of bribes to be paid to officials to receive that support) would be smaller. This is because in regions with more corruption the illegal mechanisms for securing transfers are likely to be more prevalent. As a result, the cost for the household of reporting the full extent of remittances (in case they lose the state transfers) is likely to be lower. Since higher $\mu$ corresponds to higher underreporting, it is expected that $\gamma_{1}$ would be negative.

Second, underreporting could be related to the extent of the household's dependency on state support. Low income/wealth households are likely to be more vulnerable to a possible loss of state provided benefits and are, therefore, likely to underreport the true extent of remittances they receive from abroad. We proxy this dependence/vulnerability by including a dummy variable for sub-standard housing. We, therefore, expect that $\gamma_{2}$ would have a positive sign. Similarly, households with different potential income may have different levels of dependence on state support and therefore different propensity to underreport remittances. We included the average age of working-age adults in the household to capture this effect. Since age may not necessarily translate into higher potential income - not in agriculture and most likely not in an urban environment where rapidly changing technology and implicit barriers to entry into the civil service left elder workers at a disadvantage - the sign of $\gamma_{3}$ is uncertain.

The specification for the conditional mean function includes all usual suspects as control variables. The presence of migrants from the household is an important determinant of remittances, and so we include the number of migrants in the household as well as its squared value to capture any nonlinearity. In addition, we control for the following household-level characteristics: (i) household size; (ii) percent of household members under 6 years of age; (iii) percent of household members above 64 years of age; (iv) percent of women in the household; (v) indicator variables to distinguish the rural and non-capital urban areas from the capital; and (vi) an indicator variable of excellent housing.

For the labor supply equation (i.e., stage two), the dependent variable is daily per capita hours supplied by the household. It is hypothesized to depend on the level of actual remittances, the level of unemployment in the household's region, and two sets of household level control variables. The first set of control variables relate to household composition and location and it is comprised of the variables (i) to (v) above. The second set is more specific to the ability of the household to supply labor and includes: (vii) age of the household head and its squared value; (viii) average age of working-aged household members and its squared 
value; (ix) an indicator or whether the household head is male; and (x) the percent of adult household members with post-secondary education.

\section{B. Model Estimation}

Maximum likelihood estimation of the remittance model (equation 8) and the labor supply model (equation 12) was accomplished using MATLAB. Both likelihood functions were jointly maximized and expected actual remittances (equation 9) were simultaneously calculated along with other model parameters. Note that the parameter $\theta$ in equation 8 is allowed to vary over the sample according to $\theta_{\mathrm{i}}=1 / \mu_{\mathrm{i}}$ (vid equation 13$)$. Estimation results are presented in Table 1.

Of particular interest is the model's quantification of underreporting. The variables hypothesized to be associated with the parameter measuring the degree of underreporting, $\mu$, have their expected signs and two of them are statistically significant. In order to test whether $\mu$ is statistically different from zero, the model was re-estimated without the correction for underreporting - that is, assuming that the $\mu_{\mathrm{i}}=0$ for all $i$. This can be accomplished by recognizing that the density in (4) becomes the conventional density associated with a normally distributed regression model, that (8) becomes the likelihood for the conventional censored regression model, and that (10) converges to (9). Joint maximum likelihood estimation of the resulting remittance and labor supply system generates a log likelihood of $-19,226.84$. A likelihood ratio test of the hypothesis that $\mu_{i}=0$ for all i yields a chi-square test statistic with four degrees of freedom of $21.76(p=0.0002)$. Therefore we conclude that the sample data provide evidence of underreporting of remittances.

Our corrected model suggests that households underreport remittances by 30 percent on average. And if underreporting leads to the observed remittance data having a sharply attenuated variance, parameter inflation - rather than attenuation — can result if the underreported variable is used as a regressor in a subsequent model. This is, in fact, the case for the data analyzed. For the two-step tobit model without the measurement error correction (that was estimated to provide the likelihood ratio test of whether $\mu$ equaled zero), the coefficient on remittances was estimated to be -2.85 , or almost three times larger than that from the measurement error model.

The conditioning variables in the remittance equation have some interesting insights to offer as well. As expected, the presence of migrants in the household is positively associated with the amount of remittances received, albeit with a declining strength. In addition, remittances decline with household size. This may be because larger households are perceived (by both the migrants as well as the out-of-household remitters) as more secure/less vulnerable, requiring less to sustain their consumption and livelihood. It could also be that the bequestrelated motives are weakened as the migrant faces competition from other members of the household for an inheritance. Finally, larger households may have more opportunities to share risks. Therefore, to the extent that remittances are (self-enforceable) contracts to share risks, larger households will be less likely to receive remittances.

In terms of the composition of the households, it is interesting to note that families with more children and elderly people may receive less in transfers - perhaps reflecting their needs 
(which are typically more modest, compared to younger adult members of households). In terms of the gender composition, households with a greater share of women receive more. This could be the result of a higher demand imposed on families by costs associated with the presence of women in families, such as wedding/marriage- or health-related expenditures. Note that households from non-capital urban and rural areas receive less in transfers than households from the capital. Finally, regarding the effect of receiving family's wealth on remittances, as predicted the households with "excellent" housing receive less.

In the second stage regression, the impact of remittances on hours supplied to the market is as predicted. The coefficient is negative and significant and its magnitude is rather large. Indirectly, this serves a blow to the notion that remittances may help relax budget constraints for families staying in country and correspondingly help expand their production possibilities frontier. The average calculated elasticity of labor supply with respect to remittances is -0.23 and the average marginal effect of remittances suggests that for every 100,000 dram (approximately \$190, if measured at 2004 exchange rate) annual increase in remittances, per capita daily labor supply will decline by 0.8 hours. ${ }^{4}$ Or assuming 250 eight hour working days per year, a 100,000 dram increase in annual remittances is predicted to lead to about a one-month reduction in labor supply per year.

Other findings of this regression are also worth flagging: (i) the level of regional unemployment substantially limits the ability to supply labor; (ii) households with more highly educated members supply almost 2 more hours of labor per capita than those without (iii) the presence of both elderly and children in families result in more hours supplied to the market (even though they themselves do not work); and (iv) the residents of rural households on average work almost an hour longer than those in Yerevan, while the latter work almost half-an-hour more than non-capital urban dwellers. Finally, it is interesting to note that even after controlling for the share of elderly and children in the household (because their contribution is zero), larger households supply fewer aggregate hours to the market than smaller households. This supports our earlier conjecture that family size could provide additional benefits (such as insurance against volatility and vulnerability) and, therefore, lead to fewer hours worked.

\section{Conclusions}

We have developed an econometric procedure to control for the potential errors associated with reporting/measurement issues. The methodology allows for estimating both the proportion of responses misclassified as zero and for correcting the unconditional expectation of the mis-measured, censored variable. The developed methodology was applied to household-level data from Armenia.

We find strong evidence of systematic under-reporting of remittances in Armenia. After controlling for underreporting, we find that remittance-receiving households in Armenia

${ }^{4}$ The average marginal effect can be shown to approximately equal $\alpha$ (see equation 11 ) times the proportion of households reporting a non-zero labor supply, and is therefore smaller in absolute value than the estimated $\alpha$ (Table 1). 
work fewer hours. We caution against inferring total welfare effects of the remittance flows given our partial equilibrium setting. While unable to account for productivity loss, our results do shed some light on a potential drawback of remittances in analyzing data from Armenia. While remittances may ameliorate the effects of poverty and have a measurable impact on the aggregate demand in a developing country, to the extent that they also provide disincentives to work for the members of the receiving households, their economy-wide benefits may be overstated. 
Table 1. Joint Model Estimation

\begin{tabular}{|c|c|c|c|c|c|}
\hline \multirow[b]{2}{*}{ Constant } & \multicolumn{2}{|c|}{$\begin{array}{l}\text { Remittance Equation } \\
\left.\text { Dep. Var.: Remittances ( } 10^{5} \text { drams }\right)\end{array}$} & & \multicolumn{2}{|c|}{$\begin{array}{l}\text { Labor Supply Equation } \\
\text { Dep. Var.: Per Capita Hours }\end{array}$} \\
\hline & 3.784 & $(9.331)$ & & & \\
\hline InCorruption & $-0.408 * * *$ & $(0.154)$ & $\operatorname{lnMu}$ & & \\
\hline BadHouse & $1.220 * * *$ & $(0.330)$ & & & \\
\hline lnAvWorkAge & -0.980 & (2.587) & & & \\
\hline Migrants & $5.850 * * *$ & $(0.387)$ & & & \\
\hline Migrants-sq. & $-1.033 * * *$ & $(0.116)$ & & & \\
\hline $\mathrm{E}\left[\mathrm{R}^{*}\right]$ & & & & $-0.954 * * *$ & $(0.079)$ \\
\hline Constant & $-3.074 * * *$ & $(0.456)$ & & $-2.837 * * *$ & $(1.060)$ \\
\hline HHsize & $-0.293 * * *$ & $(0.062)$ & & $-0.154 * * *$ & $(0.033)$ \\
\hline$\%$ Kids & -0.291 & $(0.868)$ & & $1.578 * * *$ & $(0.425)$ \\
\hline$\%$ Elderly & -0.697 & $(0.562)$ & & $1.257 * * *$ & $(0.352)$ \\
\hline$\%$ Women & $1.040^{* *}$ & $(0.442)$ & & -0.131 & $(0.256)$ \\
\hline Urban & $-0.421 * *$ & $(0.208)$ & & $-0.400 * * *$ & $(0.109)$ \\
\hline Rural & $-1.383^{* * *}$ & $(0.256)$ & & $1.115^{* * *}$ & $(0.122)$ \\
\hline Excellent.House & $-0.968 * * *$ & $(0.382)$ & & & \\
\hline Unemployment & & & & $-7.809 * * *$ & $(0.865)$ \\
\hline Age & & & & -0.188 & $(0.236)$ \\
\hline Age-sq. & & & & 0.026 & $(0.021)$ \\
\hline AvWorkAge & & & & $4.938^{* * *}$ & $(0.488)$ \\
\hline AvWorkAge-sq. & & & & $-0.603 * * *$ & $(0.061)$ \\
\hline HHMale & & & & $0.465^{* * *}$ & $(0.108)$ \\
\hline$\%$ PostSec & & & & $1.877 * * *$ & $(0.162)$ \\
\hline Sigma & $4.859 * * *$ & $(0.251)$ & & & \\
\hline Tau & & & & $2.952 * * *$ & $(0.043)$ \\
\hline
\end{tabular}


Table 2. Definitions of Variables

\begin{tabular}{|c|c|c|}
\hline Variable Names & Description & Source \\
\hline Hours Worked & $\begin{array}{l}\text { Per capita hours supplied to the market by the working-age } \\
\text { members of the household. The following number of hours } \\
\text { were assumed and aggregated across the household members: } \\
4 \text { for part time, } 8 \text { for full time, } 10 \text { for overtime, and } 0 \\
\text { otherwise. }\end{array}$ & $\begin{array}{l}\text { Integrated Living } \\
\text { Standards } \\
\text { Measurement } \\
\text { Survey (ILSMS) }\end{array}$ \\
\hline Remittances & $\begin{array}{l}\text { Annual household remittances received from outside the } \\
\text { country in } 100,000 \text { dram }\end{array}$ & ILSMS \\
\hline Migrants & Number of household members living out of country & ILSMS \\
\hline Age & Age of the household head. & ILSMS \\
\hline AvWorkAge & Average age of working-age members of the household. & ILSMS \\
\hline HHMale & Dummy for male household head. & ILSMS \\
\hline$\%$ PostSec & Percent of household members with post-secondary education. & ILSMS \\
\hline \%Elderly & Percent of household members above 64. & ILSMS \\
\hline$\%$ Kids & Percent of household members under 6. & ILSMS \\
\hline \%Women & Percent of women in the household. & ILSMS \\
\hline HHsize & Number of household members. & ILSMS \\
\hline $\begin{array}{l}\text { ExcellentHouse, } \\
\text { BadHouse }\end{array}$ & $\begin{array}{l}\text { Dummy variables based on household members' assessment } \\
\text { of their housing conditions (other options specified in the } \\
\text { questionnaire included GoodHouse and NornalHouse). }\end{array}$ & ILSMS \\
\hline Rural, Urban & $\begin{array}{l}\text { Dummy variables to distinguish the rural and non-capital } \\
\text { urban areas from the capital. The left-out category is capital } \\
\text { Yerevan. }\end{array}$ & ILSMS \\
\hline Corruption & $\begin{array}{l}\text { Share of respondents in every region who mentioned } \\
\text { corruption and absence of law and order as obstacles for rising } \\
\text { living standards. }\end{array}$ & $\begin{array}{l}\text { Yaganyan and } \\
\text { Shahnazaryan } \\
(2001), \text { Table } 5 \text {. }\end{array}$ \\
\hline Unemployment & Region-wide unemployment rate among men. & $\begin{array}{l}\text { Authors' } \\
\text { calculations based } \\
\text { on ILSMS. }\end{array}$ \\
\hline
\end{tabular}




\section{References}

Acosta, P., 2006, "Labor Supply, School Attendance and Remittances from International Migration: The Case of El Salvador." World Bank Policy Research Working Paper No. 3903, Washington, D.C.

Acosta, P., Calderon, C., Fajnzylber, P., Lopez, H., 2006, "Remittances and Development in Latin America," World Economy 29(7): 957-987.

Aigner, D., K. Lovell, and P. Schmidt, 1977, "Formulation and Estimation of a Stochastic Frontier Production Models," Journal of Econometrics 6: 21-37.

Alesina, A. and P. Giuliano, 2007, "The Power of the Family," mimeo. Available via the Internet: http://www.economics.harvard.edu/faculty/alesina/papers/powerfamily.pdf

Ahlburg, D., 1991, "Remittances and Their Impact: A Study of Tonga and Western Samoa," Canberra: National Centre for Development Studies, Research School of Pacific Studies, the Australian National University.

Amuedo-Dorantes, C. and S. Pozo, 2006, "Migration, Remittances, and Male and Female Employment Patterns," American Economic Review (AEA Papers and Proceedings), 96(2): 222-226.

Bauer, T. K, and K. F. Zimmerman, 1999, "Assessment of Possible Migration Pressure and Its Labor Market Impact Following EU Enlargement into Central and Eastern Europe," Research Report 3, IZA, Bonn, Germany.

Central Bank of Armenia, 2006, "Analytical Study Based on the Survey on Money Transfers Received From Abroad by the Households in Armenia in 2005."

de la Briere, B., E. Sadoulet, A. de Janvry, and S. Lambert, 2002, “The Roles of Destination, Gender, and Household Composition in Explaining Remittances: An Analysis for the Dominican Sierra,' Journal of Development Studies 68(2):309-28.

Faini, R., 2003, "Is the Brain Drain an Unmitigated Blessing?” Discussion Paper 2003/64. Helsinki, UNU/WIDER.

Freund, C. and N. Spatafora, 2008, "Remittances, Transaction Costs and Informality," Journal of Development Economics 86:356-366.

Funkhouser, E., 1992, “Migration from Nicaragua: Some Recent Evidence,” World Development 20: 1209-1218.

Goldfarb, R., O. Havrylyshyn, and S. Magnum, 1984, "Can Remittances Compensate for Manpower Outflows: The Case of Philippine Physicians," Journal of Development Economics 15: 1-17.

Greene, W.H., 2003. Econometric Analysis. Prentice Hall, Upper Saddle River, New Jersey.

Grigorian, D. and T. Melkonyan, 2008. "Microeconomic Implications of Remittances in an Overlapping Generations Model with Altruism and Self-Interest," IMF Working Paper WP/08/19. 
Hanson G., and C. Woodruff, 2003, "Emigration and Educational Attainment in Mexico," unpublished.

Hancilova, B. and A. Minasyan, 2005. "Labor Migration from Armenia in 2002-05: A Sociological Survey of Households," OSCE Armenia.

International Organization of Migration, 2002, "Irregular Migration and Smuggling of Migrants from Armenia."

Institute for War and Peace Reporting, 2000, "Brain Drain in Armenia." Available via the Internet: $\underline{\text { http: } / / \text { iwpr.net } / \mathrm{p}=\mathrm{crs} \& \mathrm{~s}=\mathrm{f} \& \mathrm{o}=162050 \& \mathrm{apc} \text { state }=\text { henicrs } 2000}$

Itzigsohn, J., 1995, "Migrant Remittances, Labor Markets, and Household Strategies: A Comparative Analysis of Low-Income Household Strategies in the Caribbean Basin," Social Forces 74(2): 633-655.

Jrbashian, N., 2001, "Representation of Vulnerable and Extremely Poor Population in Marzes and the Communities of RA: Comparative Analysis," an Interim Poverty Reduction Strategy Paper.

Konica, N. and R. K. Filer, 2005, “Albanian Emigration: Causes and Consequences,” Working Paper.

Lopez Cordoba, E., 2004. "Globalization, Migration, and Development: The Role of Mexican Migrant Remittances," mimeo. The Inter-American Development Bank, Washington, D.C.

Massey, D.S., R. Alarcon, J. Durand, and H. Gonzalez, 1987, "Return to Aztlan: The Social Process of International Migration from Western Mexico," Berkeley: University of California Press.

Massey, D.S. and E.A. Parrado, 1998, "International Migration and Business Formation in Mexico," Social Science Quarterly 79(1): 1-19.

McKenzie, D., 2005, "Beyond Remittances: The Effects of Migration on Mexican Households," in C. Ozden and M. Schiff (eds) International Migration, Remittances and the Brain Drain, The World Bank: Washington D.C.: 123-148.

Osili, U. O., 2007, "Remittances and Savings from International Migration: Theory and Evidence Using a Matched Sample," Journal of Development Economics 83: 446465.

Rapoport, H. and F. Docquier, 2005, “The Economics of Migrants' Remittances,” Discussion Paper No. 1531, Institute for the Study of Labor, Bonn, Germany.

Ravallion, Martin, 2003, "Measuring Aggregate Welfare in Developing Countries: How Well Do National Accounts and Surveys Agree?" The Review of Economics and Statistics 85(3): 645-652.

Roberts, B. W., 2004 "Remittances in Armenia: Size, Impacts, and Measures to Enhance Their Contribution to Development," Special Study, U. S. Agency for International Development, Yerevan, Armenia. 
Sana, M. and D.S. Massey, 2005, "Household Composition, Family Migration, and Community Context: Migrant Remittances in Four Countries," Social Science Quarterly 86(2): 509-528.

Selby, H.A. and A.D. Murphy, 1982, "The Mexican Urban Household and the Decision to Migrate to the United States," ISHI Occasional Papers in Social Change \#4. Philadelphia: Institute for the Study of Human Issues.

Stapleton, D. C. and D. J. Young, 1984, "Censored Normal Regression with Measurement Error on the Dependent Variable," Econometrica 52(3): 737-760.

UNDP, 1999, Labour Market in Armenia: Analysis and Policy. Available via the Internet: http://www.undp.am/docs/publications/publicationsarchive/labourmarket.pdf

U.S. Department of State, 2002. "Armenia: Country Reports on Human Rights Practices, 2001," Bureau of Democracy, Human Rights, and Labor. Available via the Internet: http://www.state.gov/g/drl/rls/hrrpt/2001/eur/8221.htm

USSR Statistical Handbook, 1988.

van Dalen, H.P., G. Groenewold, and T. Fokkema, 2005, "The effect of remittances on emigration intentions in Egypt, Morocco, and Turkey," Population Studies 59(3): 375-392.

White, H., 1982, “Maximum Likelihood Estimation of Misspecified Models," Econometrica 53: $1-16$.

World Bank, 2007, "The Caucasian Tiger: Sustaining Economic Growth in Armenia," Washington, DC.

World Bank, 2006, "Diaspora Networks and the International Migration of Skills: How Countries Can Draw on Their Talent Abroad," (ed.) Y. Kuznetsov. Washington, DC.

World Bank, 2005, "Remittances: Development Impact and Future Prospects," (eds.) S. M. Maimbo and D. Ratha. Washington, DC.

Woodruff, C. and R. Zenteno, 2007, "Migration Networks and Microenterprises in Mexico," Journal of Development Economics 82, pp. 509-528.

Yang, D., 2006, "International Migration, Remittances, and Household Investment: Evidence from Philippine Migrants' Exchange Rate Shocks," forthcoming in Economic Journal. 